\title{
Lung Inhomogeneity Correction
}

National Cancer Institute

\section{Source}

National Cancer Institute. Lung Inhomogeneity Correction. NCI Thesaurus. Code C152097.

Adjustment of radiation therapy measurements for the effects of increased transmission through lung tissue in the treatment of thoracic malignancies. 